\title{
Microcontroller based Medicine Dispenser and Reminder
}

\author{
Kunal Jagdale \\ UG Scholar \\ Dept. of Electrical Engineering \\ SVITS, Indore, India
}

\author{
A. Siddhartha Rao \\ UG Scholar \\ Dept. of Electrical Engineering \\ SVITS, Indore, India
}

\author{
Raman Hora \\ UG Scholar \\ Dept. of Mechanical \\ Engineering \\ SVITS, Indore, India
}

\begin{abstract}
The main objective of the project is to remind and dispense medicine at right time to the right person automatically from a single machine. The ratio of nurses per patient in developing countries is very low along with this the availability of 24 hours' medical staff is also ambiguous which has led to the occurrence of easily avoidable death as well critical situation leading to a ruckus in the health industry. The medical dispensers which are available today are expensive and there is less availability of products that are a combination of a reminder and a dispenser. Automatic medication dispenser is designed for people, who undertake medication without professional supervision,
\end{abstract}

The product can be used by an individual as well as multiple patients. It saves the person from the error-prone task of administrating wrong medicine at the wrong time.The prominent components of this project are push buttons interfaced with a microcontroller, LCD Display, a motor controller, an alarm system, multiple pill container, and dispenser. The prominent operation is to facilitate the patient in taking correct medication and avoid any mishap due to negligence or improper care. The Alarm system is designed to provide two types of indications one by lighting an LCD and the other by providing a beep sound.

The major goal is to keep the device easy to use and economic. The software that works is dependable and stable. The elderly population will be gain enormously from the device as it can replace sumptuous medical care. This can be a boon for the elderly as well as the poor sector of the society.

\section{Keywords}

Microcontroller, Medicine Dispenser and Reminder, Arduino, Motor Controller

\section{INTRODUCTION}

In India and other developing countries, the health industry faces a lot of problems that can be in the form of lack of availability of medical staff, less qualified doctors as well as nurses, the ratio of nurses to the patient is also very low due to which the risk of health hazard increases [1]. This issue is majorly concerned with the Government hospitals as well as cheap health care centers which although provide cheap healthcare but facilities provided are low on quality as well as negligence of staff for patient health is very high. The population of patients in the government hospitals is very high due to which doctors are not able to able pay attention to each and every patient so there are high chances of error in medicine provision to the patient [2].

Senior citizens consume medication in the form of pills on a daily basis. Due to the age factor, they often tend to forget the right time to take the medicine as well as the right medicine [3].Fostering the aged is a major concern for every family and the less aged are responsible for the care and management of the doddering people. In the present scenario, as the working hours have increased and people are tangled on the professional front, it is difficult to pay attention to the elderly. Most of the family in this contemporary age are nuclear so taking care of old at their dotage becomes difficult. It is difficult for family members to be available all the time to support the aged. Today in our society most families are nuclear, Elderly would prefer to remain independent and their desire for independence is natural but it is a worry for their children [4]. Sometimes despite their best effort, the aged fail to remember to take medication on time, we want to improve the quality of life for senior citizens, as well as the poor sector of the society by preparing regimen automatically to eliminate non-adherence cases [5].

This project is an attempt to create something that is more useful than current products on the market, by minimizing the work that the user must do in order to regularly take their medication. Automatic Medication dispenser is one such approach to help them take their medicines efficiently [6]. Current pill dispensing machines are expensive and are complicated in terms of working. The pill dispensing machine that we are proposing will automatically prepare the right combination of pills and will be capable of accommodating more medications [6]. This includes both the hardware and software concept design. It contains the Microcontroller which is the heart of the system managing the overall operation of the system. It provides LCD display and the Buttons interface to interact with the external world. The text display provides required knowledge about the setting and also displays the present setting operation. The program provides a lucid understanding of the system with much confusion. The Motor controller is programmed so that at the right time the timer interrupts the motor at the right time to rotate and make the pills/capsules drop into the output poach [7]. It also provides a Beep sound through the buzzer drawing the attention of the patient to take action immediately. When the user presses the next button the alarm beep sound is switched off and dispensing process starts [8].

\section{COMPONENTSREQUIRED}

This section enlists all the components that we used in order to materialize our project.

\subsection{Arduino Mega2560}

The Arduino Mega2560 is a microcontroller board, which has 54 digital I/O pins (Input/output Pins). Of these 54 pins, 14 can also be used as PWM outputs [9]. Apart from the aforesaid detail, the processor also has 16 analog inputs, 4 hardware serial ports, a $16 \mathrm{MHz}$ crystal oscillator, a power jack, a USB connection, an ICSP header and a reset button.

\subsection{Motor Driver (L293D)}

For the purpose of providing the user with the ease of access and friendly interfacing, the L293D motor driver is made available. In order to easily utilize driver IC's pin functions, the pins of the L293D motor driver IC are connected to the 
connectors. A good quality, single sided non-PTH PCB is used for mounting the L293D motor driver. Having the capacity to drive upto 1 Ampere of current per bridge with a supply voltage of $24 \mathrm{~V}$, the L293D made itself known as a Dual Full Bridge driver [10].

Table 1. Table captions should be placed on the table

\begin{tabular}{|l|l|}
\hline Power Supply & $\begin{array}{l}\text { External Power 9V to } \\
24 \mathrm{~V} \text { DC }\end{array}$ \\
\hline Size (Dimensions) & $\begin{array}{l}45 \mathrm{~mm} \times 35 \mathrm{~mm} \times 35 \mathrm{~mm} \\
(1 \times \mathrm{b} \times \mathrm{h})\end{array}$ \\
\hline
\end{tabular}

\section{3 liquid Crystal Display}

A very popular display widely used in many digital watches and portable computers is the liquid crystal display. Two sheets of a polarizing material are used with the insertion of a liquid crystal between them. The crystals align in such manner so that the light cannot pass through them when an electric current is passed through them. The $16 \times 2$ intelligent alphanumeric dot matrix display is capable of displaying 224 different characters and symbols. It requires a single power supply $(+5 \mathrm{~V})[11]$.

\subsection{Motor}

A motor is an electrical machine converting electrical energy into mechanical energy. The principle of working of an electric motor is that whenever a current carrying coil is placed in a magnetic field, it would experience a mechanical force exerted on it, thus it works on the principle of electromagnetic induction. The direction of movement of the coil is decided by Fleming's Left Hand Rule. Motors used in the project are geared running at $30 \mathrm{rpm}$ at $12 \mathrm{~V}$ supply [12].

\subsection{Real Time Clock (DS1302)}

Containing 31 bytes of static RAM along with a real-time clock/calendar, the DS1302 Trickle Charge Timekeeping Chip communicates via a simple serial interface with the microprocessor. The real-time clock/calendar plays a vital role in the working of the chip by providing information of the seconds, minutes, hours, day, date, month and year [13]. Operating in either of the two formats i.e. 24-hour and 12hour, with the provision of AM/PM indicator, the clock also adjusts the end-of-the-month date for months with less than 31 days.

\subsection{Buzzer}

The buzzer is basically an electronic sounder with the characteristic of making a high pitched tone like a Son Alert. This device typically makes itself usable in automobiles and household appliances like oven. This is a small $12 \mathrm{~mm}$ round speaker that operates around the audible $2 \mathrm{kHz}$ range [14].

\subsection{Push Buttons}

In simple words, the push buttons are used to set or reset data, thus they are nothing but setting buttons with a straight functionality. We, in our project, utilize the push buttons for setting, incrementing and entering text data.

\section{POWER SOURCE}

The power pins are as follows:

-VIN- Provides input voltage for Arduino board when connected to external power source (as opposed to 5 volts from the USB connection or another regulated power source).
Voltage can be supplied with the help of a pin or via power jack.

.5V- The regulated power supply used to power the microcontroller and other components on the board. This can come either from VIN via an on-board regulator, or be supplied by USB or another regulated $5 \mathrm{~V}$ supply.

-3V3- A 3.3-volt supply generated by the onboard regulator. Maximum current draw is $50 \mathrm{~mA}$.

-GND- Ground pins.

\section{METHODOLOGY}

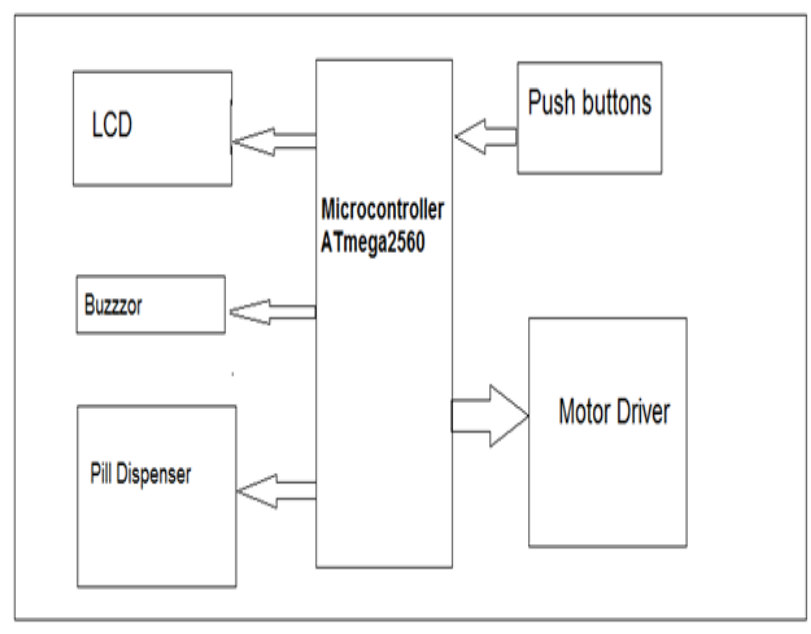

Figure. 1 Block diagram of Medicine Dispenser

The construction of the project involves steps: -

\subsection{Electronic Part}

3.1.1 The Arduino ATMEGA 2560 is used for the project and its basic function is tested with help TX and RX lights while connected to the power source.

3.1.2 The following files are added to the library of the Arduino

$\begin{aligned} \text { i. } & \text { Wire.h } \\ \text { ii. } & \text { EEPROM.h } \\ \text { iii. } & \text { DS1302RTC.h } \\ \text { iv. } & \text { Liquidcrystal.h }\end{aligned}$

3.1.3 Interfacing of Arduino is done with LCD to display time, date, medicine name, no. of medicine to be dispensed 3.1.4 Interfacing of a real-time clock (RTCDS1302)with the Arduino as well as the LCD that allows LCD to show correct time on its display. The RTC also helps in setting up the alarm and providing a signal to the buzzer [15].

3.1.5 Interfacing of push button with Arduino is done to set the time as well to select the type of medicine to be dispensed. It also provides the facility of dispensing the amount of medicine on required time.

3.1.6 Interfacing of motor driver is done with Arduino to control the no. of rotation of the motor [16].

3.1.7 Interfacing of a buzzer with Arduino is done to make a sound during an alarm. 


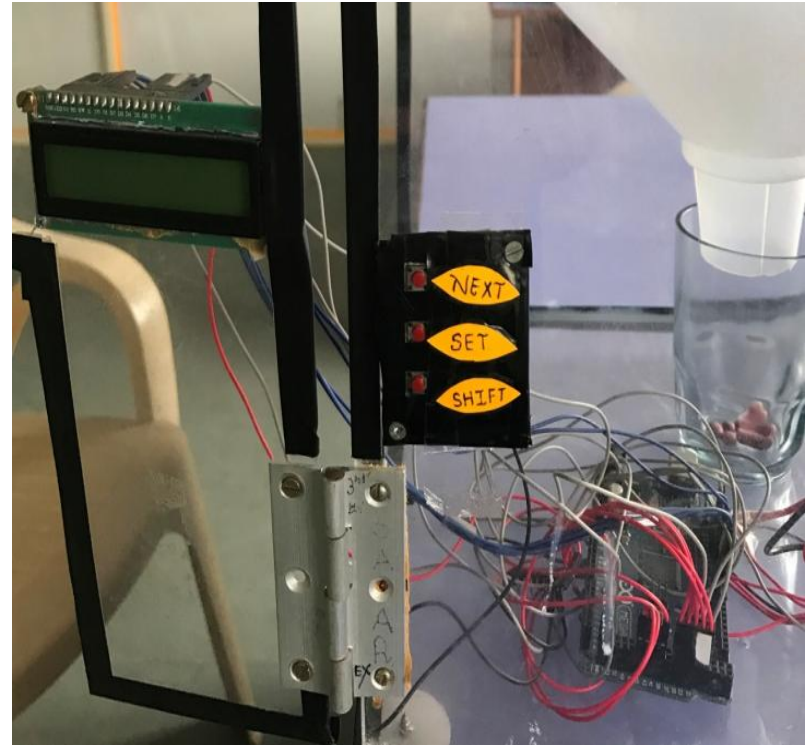

Fig.2 The push button and LCD connected to the Arduino

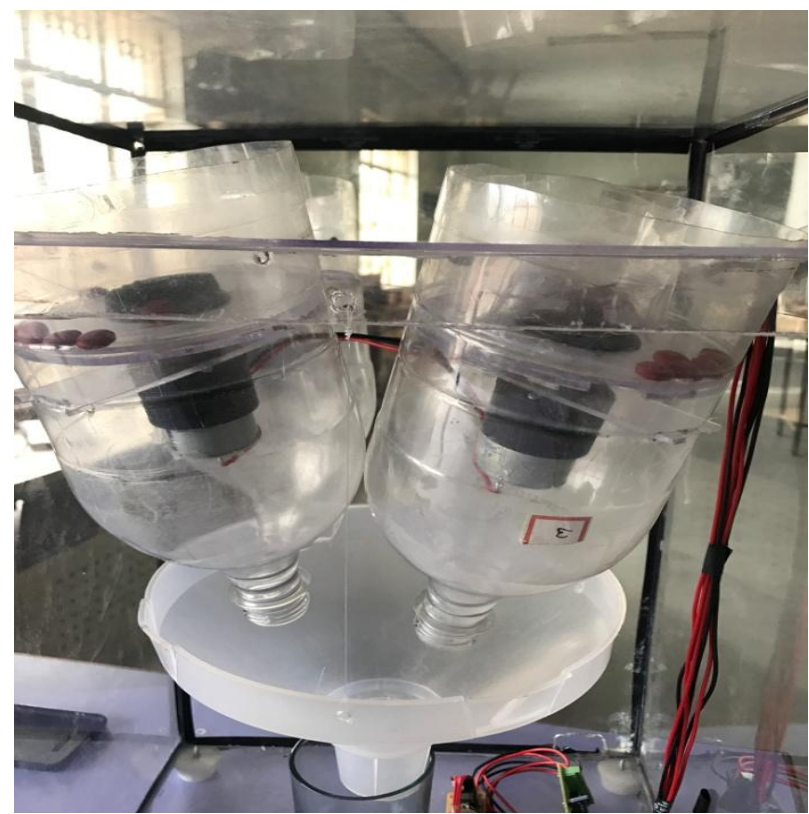

Fig.3 Motor driver connected to circular plates at the center

\subsection{Mechanical Part}

\section{OUTER BODY}

The outer body is made by cutting 4 rectangles of dimension $45 * 35 \mathrm{~cm}$ and squares of $35 * 35 \mathrm{~cm}$ which is joined together to form a Cuboid. The material used in the formation of a cuboid is acrylic which provides a transparent finish to the outer body of the dispenser. A magnetic lock is fitted outside in order to open and close the dispenser.

\section{INNER BODY}

A square sheet of dimension $35 * 35 \mathrm{~cm}$ is cut out from an acrylic sheet and four circles of required diameter are cut from the respective square sheet that can hold up the cylindrical water bottles that dispense medicine into the funnel. This square sheet is placed $45 \mathrm{~cm}$ above the base.

Four water bottles having an open base and cylindrical surface area are placed in the slots with the help of screws as shown in figure 3.2 .
Eight circular sheets having a dimension equal to the base of water bottles are cut and a hole of diameter $0.5 \mathrm{~cm}$ is made. The water bottles are so connected such that their mouths are adjacent to each other as shown in fig 3.2.

The circles are made to get fixed with the motor shaft as shown in the figure with 4 pairs of circles attached to the 4 DC motor. The circle along with the motor are fixed as shown in figure 3.2

A funnel is placed below the arrangement to collect the medicine.

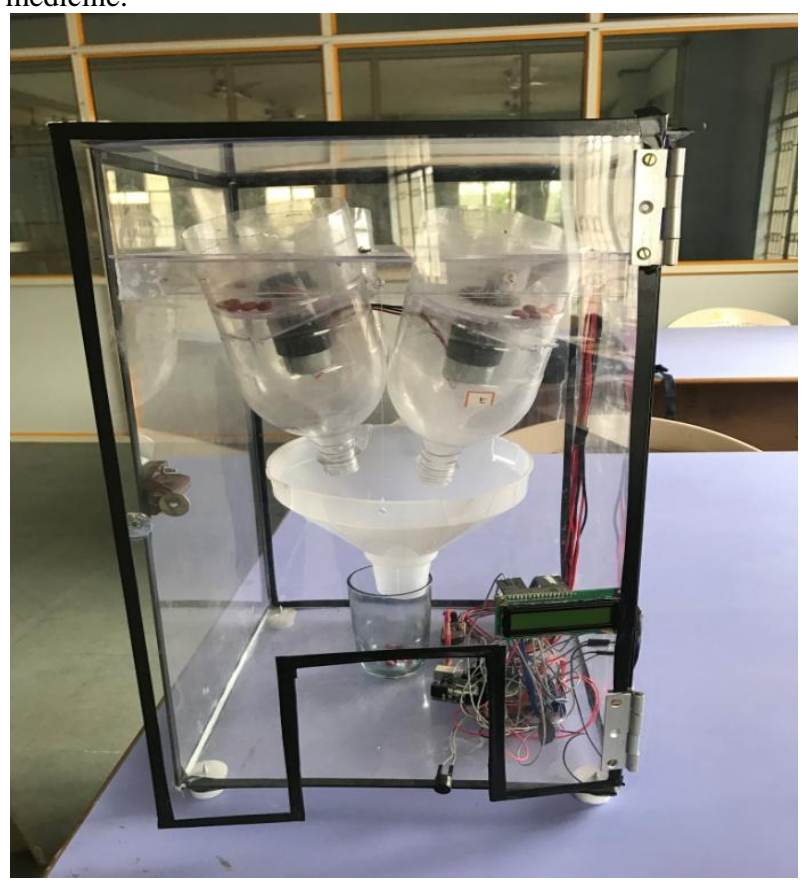

Fig. 4 Front view of medical dispenser and reminder

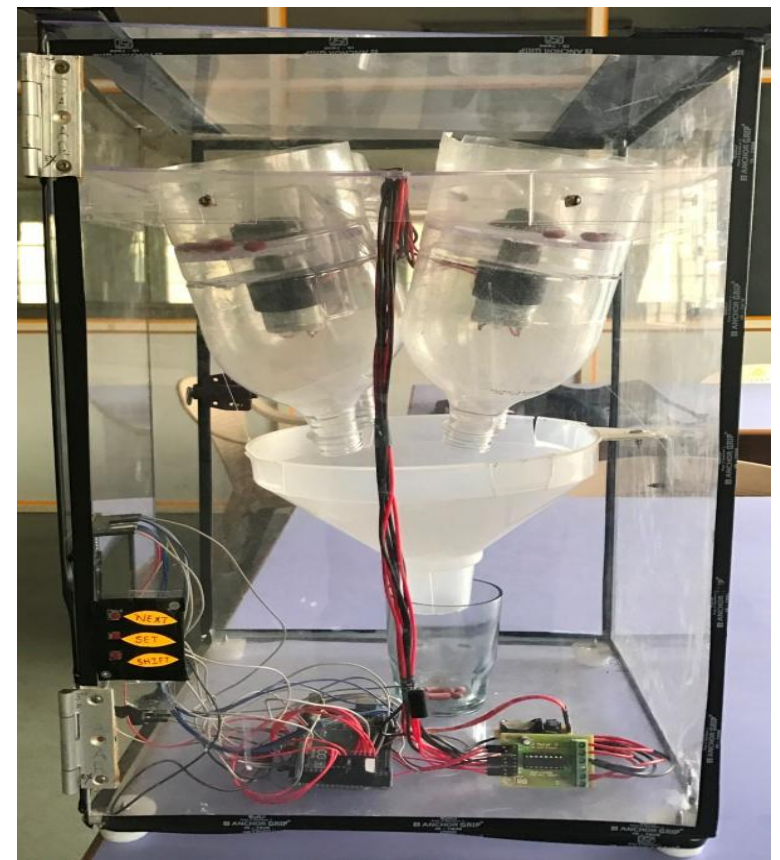

Fig. 5 Side view of the project 


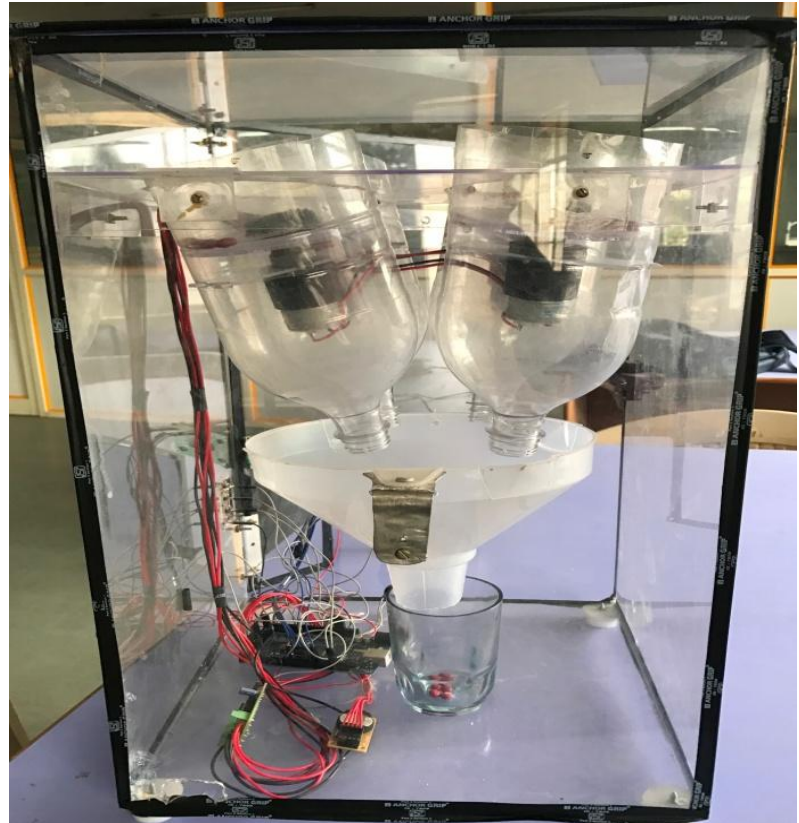

Fig. 6 Back view of the project

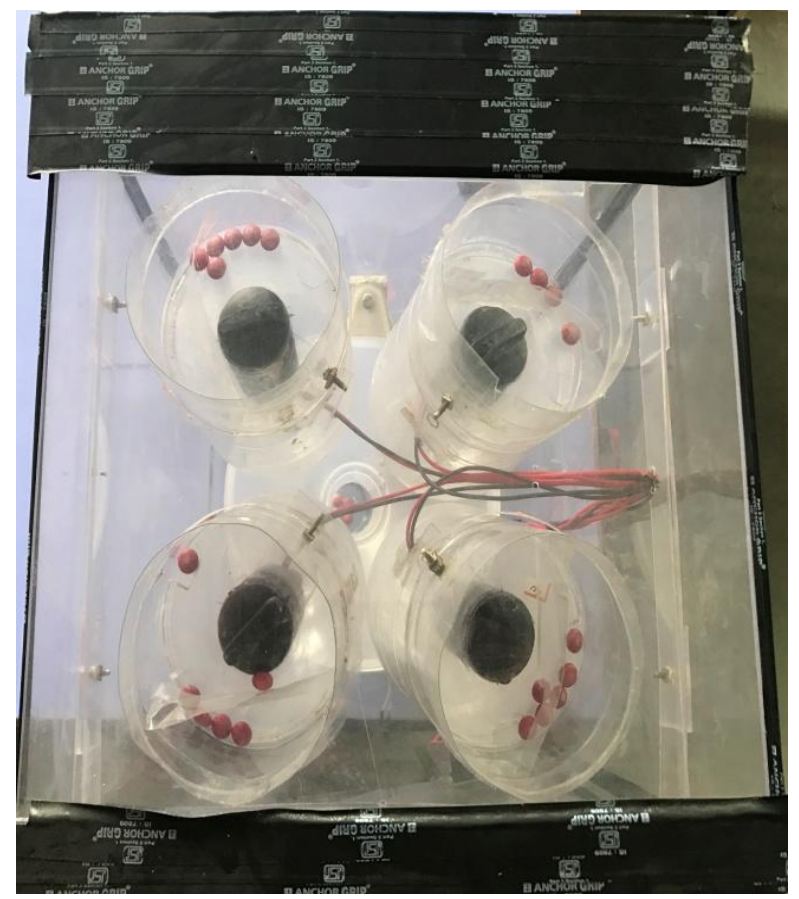

Fig.7 Top view of the medical dispenser and reminder

\section{WORKING}

The working of the medicine dispenser can be simply explained. It can be easily handled with the help of three buttons that are set button, Increment button, and Next button. The device consists of four compartments for four different medicines; a number of compartments can be increased according to the prescription. The working of this is controlled by a microcontroller, RTC, and the motor driver [17]. The motor driver gets the command which will initiate the motor action. The no. of times the motor will rotate will be equal to the no. of medicines to be dispensed. The shaft of the motor contains two circular plates, one of which is rotating and the other fixed. The diameter of both these plates is equal to the diameter of the bottle attached. The corner of the plates contains slots of the size nearly equivalent to that of one medicine. When the motor rotates and the slots of both these plates i.e. the slots of rotating plate coincides with the slots of the fixed plate, the medicine will get dispensed, which will ultimately get deposited in the container through the bottle connected at an angle of the range of 25 to 30 degrees [18].

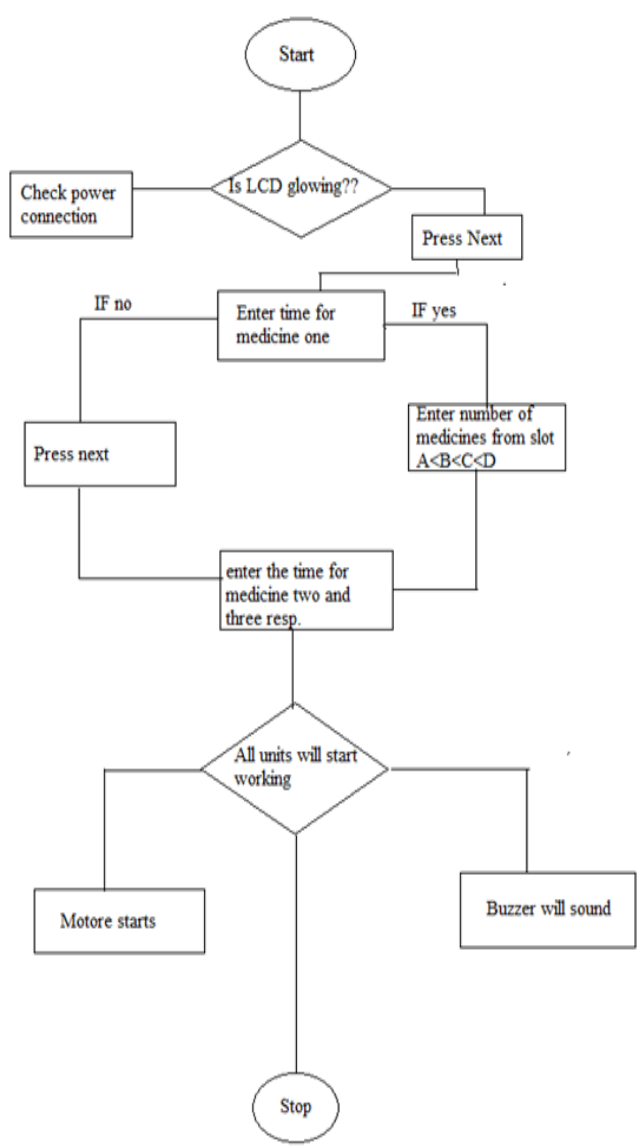

Fig. 8 Flow Chart of Medicine Dispenser

The function of three buttons used is-

1. Set button- It is used to set the medicine.

2. Increment button- It is used to date, time and No. of medicine from different compartments.

3. Next button- It is used to set the cursor to next.

After following above procedure, the buzzer will sound at the entered time and will also sound at the time of dispensing.As soon as we give the power supply to the dispenser unit, we will press the set button. After this, the LCD will display the name of the project as per loaded in the program. Now, we will press the 'NEXT' button, pursuant to which the dispenser will ask the time for dispensing medicine 1 , so we will then press 'SHIFT' button to set the time which will get saved in the RTC. Again after pressing the 'NEXT' button, the dispenser will ask as to how many medicines to be dispensed from each slot, which will be set using the 'SHIFT' \& 'NEXT' buttons. The same process will be repeated for medicine $2 \&$ medicine 3 . After setting both the quantity and time of all the medicines, we will commence the dispensing process. Now the role of buzzer comes into play. The buzzer will sound until and unless someone presses the 'NEXT' button. For the consumption of the patient, as soon as the' NEXT' button gets pressed, the machine dispenses the predefined dosage as specified and set for that particular time. 


\section{CONCLUSION}

The Automatic Medicine Dispenser works for pills and capsules of a variety of sizes. It has been found that the dispenser can be programmed for a number of days for a number of different medicines. It has the facility to send alarms three times a day and even more. It is programmed as such that allows the dispenser to dynamically change the number of times and the number of pills to be picked as per requirement.

The machine is also self-contained in the sense that it can be unplugged from the wall, picked up, and moved anywhere (with traditional wall outlets), be plugged in, and function as expected. The modularity of the design was a huge triumph in itself.

The working of the machine is very easy such that anyone can operate it and it is not so expensive that is its cost is very much less than the medicine dispenser available in the market. The programming of the controller is very easy but little bit lengthy. The working of automatic pill dispenser is very effective and user-friendly.

The major demand of the user is performance, serviceability, reliability, capital, and safety. The performance required is lightweight, easyto use for both the attendant and the patient, appropriate construction to avoid possible meddling, a vivid warning LED 70+ decibel audio alerts and good a display unit.

The product AMDR is high durability and is easy to repair. The software used is trustworthy and mechanically safe. The salient features are minimum bulkiness, small size, ability to go back to default setting. A lock for safety with safeguards the Arduino as well the Motor.

\section{FUTURE SCOPE}

From the time the pills were introduced in the medication industry the requirement of a device that can come as a substitute to the human being for delivery of medicine.

No pill dispenser to today could replace could determine the person who to give a pill to, when to give a pill and the no. of pills to be given. There are many other problems that plague the home pill user, such as someone stealing pills, forgetting to take them or having the pills available to take too many. AMDR mechanism such that it works on the principle of MECHATRONICS that is it combines the mechanics as well electronics to dispense medicine. Therefore, chances of error are very less.

Following are some of the sector that can be made better by AMDR: -

i. Hospitals:-The automatic pill dispenser can ease up the pill dispensing operation of the large as well as small health care center. With the help AMDR, the medical staff, as well as a doctor, can reduce the amount of time as well frequent checkup of every patient. This will help the doctor to give time to those patients which are in critical condition or are in greater need for attention from the medical staff

ii. Home: - Vitamins and another essential dietary supplement that is required everyday before and after a meal can become a great area of interest for the use of an automatic pill dispenser. An individual keychain key can initiate the pill dispensing for the user's personal diet regime and a buzzer can remind them when the supplements need to be taken. iii. Elderly: -The automatic pill dispenser is an excellent way for the elderly to be reminded when to take their pills and the current access key can be worn around the neck or on a bracelet.

\section{FUTUREIMPLEMENTATION}

i. Along with the medical dispenser, we can also add a syrup disperser by adding a slot for syrup dispenser and controlling the opening and closing of the valves through Arduino. This would be highly beneficial in especially in childcare centers

ii. The present project requires a person to collect medicine from the dispenser but if slider is added to the dispenser which can be done by using weighing sensor which will slide the medicine outside by calculating the difference of weight of container before and after the medicine is dispensed

iii. The security of the dispenser can be increased by making the dispenser password protected. This can be done by interfacing a keypad with Arduino.

\section{REFERENCES}

[1] Lozano, Rafael, Mohsen Naghavi, Kyle Foreman, Stephen Lim, Kenji Shibuya, Victor Aboyans, Jerry Abraham et al. "Global and regional mortality from 235 causes of death for 20 age groups in 1990 and 2010: a systematic analysis for the Global Burden of Disease Study 2010." The Lancet 380, no. 9859 (2013): 20952128 .

[2] Hall, Mark A., Elizabeth Dugan, Beiyao Zheng, and Aneil K. Mishra. "Trust in physicians and medical institutions: what is it, can it be measured, and does it matter?." The milbank quarterly79, no. 4 (2001): 613639.

[3] Peel, Elizabeth, Margaret Douglas, and Julia Lawton. "Self monitoring of blood glucose in type 2 diabetes: longitudinal qualitative study of patients' perspectives." Bmj 335, no. 7618 (2007): 493.

[4] Kymlicka, Will, and Wayne Norman. "Return of the citizen: A survey of recent work on citizenship theory." Ethics 104, no. 2 (1994): 352-381.

[5] Skhosana, Nokuthula L., Helen Struthers, Glenda E. Gray, and James A. McIntyre. "HIV disclosure and other factors that impact on adherence to antiretroviral therapy: the case of Soweto, South Africa." African Journal of AIDS Research 5, no. 1 (2006): 17-26.

[6] Peterson, Charles D., and Howard C. Anderson Jr. "The North Dakota telepharmacy project: restoring and retaining pharmacy services in rural communities." Journal of Pharmacy Technology20, no. 1 (2004): 28-39.

[7] Rast, Rodger. "System and method for providing temporal patient dosing." U.S. Patent Application 10/009,041, filed November 8, 2001.

[8] Feodoroff, Thomas J. "Blister pack medication reminder system and method." U.S. Patent 7,336,564, issued February 26, 2008.

[9] Barrett, Steven F. "Arduino microcontroller processing for everyone!." Synthesis Lectures on Digital Circuits and Systems 8, no. 4 (2013): 1-513. 
[10] Venkatesh, A. Seshanka, K. Vamsi Krishna, N. K. R. Swamy, and P. Simhachalam. "Robot Navigation System with RFID and Ultrasonic Sensors." International Journal of Engineering Research \& Science (IJOER) 2.

[11] Scheffer, T. J., and J. Nehring. "A new, highly multiplexable liquid crystal display." Applied Physics Letters 45, no. 10 (1984): 1021-1023.

[12] Reddy, Mounika Kandi. "DESIGN AND FABRICATION OF MOTORIZED SCREW JACK FOR A FOUR WHEELER." PhD diss., Jawaharlal Nehru Technological University, 2011.

[13] Chenguang, Wang, and Sun Yunqiang. "Application of serial clock chip DS1302 in temperature measuring and recording instrument [J]." Electronic Test 12 (2008): 018
[14] Koch, Martin. "Building Electric Guitars." Martin Koch. Gleisdorf, Austria (2001).

[15] Verdú Santano, Daniel. "Tecnología open-hardware para la parametrización ambiental en aplicaciones de Ingeniería." (2017).

[16] Shuvo, Riad Reza, and Md Saifur Rahman Mazumder. "Smart Curtain Control System Using Smart Phone Via Bluetooth." PhD diss., East West University, 2016.

[17] Kumar, N. Senthil, M. Saravanan, and S. Jeevananthan. Microprocessors and Microcontrollers. Oxford University Press, Inc., 2011.

[18] Adamson, I. Y. R. Toxicology of inhaled materials: general principles of inhalation toxicology. Vol. 75 Springer Science \& Business Media, 2012. 